\title{
Effects of Life - Skills Counseling In Enhancing Self-Sufficiency among High School Students
}

\author{
Surma, $\mathrm{S}^{1}{ }^{*}$, Sampathkumar ${ }^{2}$
}

\section{ABSTRACT}

The purpose of the present paper is to know the effectiveness of life-skills counseling intervention in enhancing self-sufficiency of high school students. Life-skills counseling is an educational approach, which is used to inculcate the essential life-skills in an individual to meet the challenges of everyday life. It is also known to be very effective and appropriate for present day scenario. It is easily adaptable for larger groups. High School students are in the stage of adolescence. High school students face a wide variety of problems out of which the major ones are lack of self-sufficiency, inability to manage emotions, decision-making skills etc. The present study involves 300 high school students (150 Boys and 150 Girls) who are selected from various schools in Mysore city corporation limit. High School Personality Questionnaire (HSPQ) was administered to find out the personality problems of high school students. Experimental design has been applied and Life-skills counseling intervention has been given for the experimental group. Life-skills counseling was found to be very effective in enhancing the selfsufficiency of high school students.

Keywords: Life-skills counseling for High school students, Self sufficiency of High school students, enhancing Self-sufficiency.

Life-skills are abilities for adaptive and positive behavior that enable us to deal effectively with the demands and challenges of everyday life. (WHO 1997).

Life-skills aim to increase positive and adaptive behavior by assisting individuals to develop and practice psycho-social skills that minimize risk factors and maximize protective factors (UNICEF 2003).

\footnotetext{
${ }^{1}$ Assistant Professor, Department of Psychology, Karnataka State Open University, Mysore, Karnataka, India

${ }^{2}$ Assistant Professor, Department of Psychology, University of Mysore, Mysore, Karnataka, India

*Responding Author

(C) 2016, S Surma, Sampathkumar; licensee IJIP. This is an Open Access Research distributed under the terms of the Creative Commons Attribution License (http://creativecommons.org/licenses/by/2.0), which permits unrestricted use, distribution, and reproduction in any Medium, provided the original work is properly cited.
} 


\section{Effects of Life - Skills Counseling In Enhancing Self-Sufficiency among High School Students}

In the growing years, the high school students face a number of problems like inability to handle emotions, conflicts, frustrations, anxieties about future; these may lead them towards negative risk behaviors. Life-skills counseling would be very effective to empower the young children to act responsibly take initiative and take control of the situation.

Life-skills counseling is designed to facilitate the practice and reinforcement of psychosocial skills in a culturally and developmentally appropriate way; it contributes to the promotion of personal and social development, the prevention of health and social problems, and the protection of human rights (WHO 1999).

High school students come under the stage of adolescence. According to Elizabeth B. Hurlock (1993) the adolescents undergo many changes, physical development takes place in noticeable forms. The rate of growth is very rapid during these years. Self-concept, self-confidence and self-sufficiency are the most important concepts which need to be positively enhanced during this stage.

According to Anon (2004) in India in the present scenario the ratio of adolescences is $1 / 5$ of India's total population. Recent psychological researches suggest that more adolescents are facing mental health and personality problems. Indian council of medical research reported that about 12.8 percent of 1-16 age group children suffer from mental health and personality problems.

Bugenatal and Grusec (2006) opines that adolescence is the most vulnerable age for development, when the child once entering this stage require intensive readjustment to school, social and family life. Heppnes Ruld and et al (1994) say that an inability to cope with these adolescent years may result in poor academic achievement and poor social relations and feelings of hoplessness that can lead to suicidal thoughts.

Allport .G.W (1957), the father of Modern Personality Theory suggests that psychologists and counselors should undertake the task of building a healthier "Nurturing" environment. They should help the adolescents to make value based choices, to reshape the personality of the adolescents in such a manner that the adolescents should be capable enough to overcome the behavioral problems and also to make effective decisions about life. Therefore, the present experiment was planned to enhance the self-sufficiency among High school students.

\section{METHODOLOGY}

\section{Participants}

A large number of high school students from various schools in Mysore city corporation limit were selected and assessed on HSPQ. A sample of 300 high school students (150 boys and 150 
girls) who had deficiency in self-sufficiency personality factor were selected based on HSPQ. The sample was randomly divided into experimental and control group.

\section{Research Design}

The study was conducted by using experimental design where experimental group received lifeskills counseling intervention and control group was kept constant and later compared the preassessment scores with the post assessment scores.

\section{Measures}

Personal information schedule was used to collect the general data of the high school students. HSPQ (Form A and Form B) this questionnaire is developed by R.B. Cattell (1968-69) Form-A questionnaire consist of 142 questions and Form-B 142 questions. Form A was used in pre assessment condition and Form B was used in post assessment condition to avoid carryover effects. It measures 14 primary personality factors. Each dimension is defined by two poles or extremes. Only self-sufficiency personality factor is concentrated in this paper.

\section{Procedure}

The different high schools were visited in Mysore city corporation limit during the study. Form A of HSPQ was administered to a large number of high school students and responses were scored. The students who had deficiency in self-sufficiency personality factors were selected for the study. The selected 300 participants were randomly divided into two groups. Such as experimental and control group. To assure the randomization of the sample the data was subjected to independent samples ' $t$ ' test in the pre-test. The experimental and control groups mean score and S.D. on self-sufficient personality factor were 4.36, 1.9 and 4.43, 1.9 respectively. The ' $\mathrm{t}$ ' value -.298 and $\mathrm{P}$.766, indicating a non significant difference between experimental and control groups. Thus the equating and randomization of the groups was taken care of during the pre-test situation. The experimental group was subjected to life-skills counseling intervention with the five stages of life skills counseling model (DASIE), developed by the Richard Nelson Jones. Life-skills counseling intervention was not given to the control group but was under observation by the researcher. The time schedule for intervention is one hour duration per session and two sessions per week. The total 20 sessions was conducted over a period of 3 months. After the intervention for post assessment the HSPQ Form-B was administered for both the experimental and control groups. The responses were scored and pretest and post-test data was compared using repeated measures of 'ANOVA'.

\section{Life-Skills Counseling Intervention}

Richard Nelson-Jones (2000), considered that with the knowledge of life skills person would possess awareness in each of these areas; responsiveness, realism, relating, rewarding activity, and right-and-wrong. He advocated that the life-skills counseling as a "people-centered approach for assisting clients and others to develop self-helping skills”. He designed five stage life skills 
counseling model DASIE, for helping clients to manage problems. DASIE is not only for managing or solving problems but also for addressing underlying problematic skills. The DASIE stands for; D-Develop relationship and clarify the problem, A-Assess and restate the problem in skills terms, S-State goals and plan Interventions, I-Intervene to develop life skills, E-Emphasize, take away and end.

\section{RESULTS AND DISCUSSION}

General linear model repeated measures of ANOVA are applied to know effect of life skills counseling intervention programme in pre-post test conditions.

TABLE No. 1: Mean and SD of pre-test and post-test scores on self- sufficiency of high school students of both experimental and control groups.

\begin{tabular}{|c|c|c|c|c|c|c|}
\hline \multirow{2}{*}{ Group } & \multirow{2}{*}{ Gender } & \multicolumn{2}{|c|}{ Pre-test } & \multicolumn{2}{|c|}{ Post-test } & \multirow{2}{*}{ Change } \\
\hline & & Mean & SD & Mean & SD & \\
\hline \multirow{3}{*}{ Experimental } & Boy & 4.48 & 1.89 & 7.49 & 1.23 & 3.01 \\
\hline & Girl & 4.24 & 1.96 & 7.88 & 1.17 & 3.64 \\
\hline & Total & 4.36 & 1.92 & 7.69 & 1.21 & 3.33 \\
\hline \multirow{3}{*}{ Control Group } & Boy & 4.59 & 1.89 & 4.44 & 1.86 & -0.15 \\
\hline & Girl & 4.27 & 2.00 & 4.15 & 1.85 & -0.12 \\
\hline & Total & 4.43 & 1.95 & 4.29 & 1.85 & -0.14 \\
\hline \multirow{3}{*}{ Total } & Boy & 4.53 & 1.89 & 5.97 & 2.19 & 1.44 \\
\hline & Girl & 4.25 & 1.97 & 6.01 & 2.43 & 1.76 \\
\hline & Total & 4.39 & 1.93 & 5.99 & 2.31 & 1.60 \\
\hline
\end{tabular}

TABLE No. 2: Summary results of GLM-Repeated measures of ANOVA within and between subjects for self sufficiency of experimental and control groups in pre-test and post-test situations.

\begin{tabular}{|l|l|l|l|l|l|}
\hline WITHIN SUBJECT EFFECTS & $\begin{array}{l}\text { Sum of } \\
\text { Squares }\end{array}$ & df & $\begin{array}{l}\text { Mean } \\
\text { Squares }\end{array}$ & F & p \\
\hline Time & 382.402 & 1 & 382.402 & 162.680 & .000 \\
\hline Groups & 448.935 & 1 & 448.935 & 190.985 & .000 \\
\hline Gender & 4.002 & 1 & 4.002 & 1.702 & .193 \\
\hline Time *Groups*Gender & 3.375 & 1 & 3.375 & 1.436 & .232 \\
\hline Error (change) & 695.787 & 296 & 2.361 & & \\
\hline BETWEEN SUBJECT EFFECTS & \multicolumn{5}{|l|}{} \\
\hline Groups & 415.002 & 1 & 415.002 & 107.191 & .000 \\
\hline Gender & 2.042 & 1 & 2.042 & .527 & .468 \\
\hline Group*Gender & 5.415 & 1 & 5.415 & 1.399 & .238 \\
\hline Error (change) & 1146.000 & 296 & 3.872 & & \\
\hline
\end{tabular}




\section{Effects of Life - Skills Counseling In Enhancing Self-Sufficiency among High School Students}

Repeated measures of ANOVA revealed that a significant decrease from pre to post-test situation irrespective of the groups. The $\mathrm{F}$ value $(\mathrm{F}=162.68$; $\mathrm{P}<0.001)$ found to be highly significant. Irrespective of the groups in pre-test the mean self- sufficiency score was 4.39 and increased to 5.99. With the increasing 1.60 scores, found to be significant. When increase in the selfsufficiency scores with reference to groups are concerned again a significant ' $F$ ' is observed $(F=$ 190.99; $\mathrm{p}<0.001$ ) indicating differential increasing for experimental and control groups. From mean values it is evident that experimental group had a increase of 3.33 scores (from 4.36 to 7.69) whereas control group had decrease of only 0.14 scores (from 4.43 to 4.29 ). So the increasing in the self sufficiency has been basically in the experimental group which can be attributed to the effectiveness of life skills counseling intervention. However the interaction effect between gender groups with respect to change in the scores with respect to groups and change in scores are found to be non significant. Between subject effects between groups (irrespective of conditions) together significant difference are observed $(\mathrm{F}=415.00 ; \mathrm{p}<0.001)$. However, gender group wise and interaction between groups are found to be non-significant.

It is very much evident from the result that, the Life-skills counseling intervention has enhanced self-sufficiency among high school students. Life-skills counseling promotes healthy personality, healthy interaction and behavior. The research has shown that life-skills counseling is an effective approach for primary prevention for educational and adjustment problems. The major implication of this study is that it indicates a need for a possible shift in the thinking of the health policy makers of our country and institutions. The study has implications for the good academic environment. The study can be very useful for school counselors, social workers and policy makers. Findings can be used by these specialists to design intervention programs aimed at students for the betterment of good academic achievement and to enhance the personality of students in schools and colleges.

\section{Acknowledgments}

The author appreciates all those who participated in the study and helped to facilitate the research process.

\section{Conflict of Interests}

The author declared no conflict of interests.

\section{REFERENCES}

Allport, G.W. (1957). The resolution of Inter group Tension, conclusion; National conference on Christians and Jews, New York.

Anon (2004). Wing Spread declaration non school connections. Journal of school health, 74, 233, 234.

Bugental and Grusec (2006). Hand Book of Child Psychology, John Welly and Sons. New York. Cattell, R.B. (1968-69). High School Personality Inventory manual. 


\section{Effects of Life - Skills Counseling In Enhancing Self-Sufficiency among High School Students}

Dixon, W.A., Heppner, P.P. and Ruld ,M.D. (1994). Problem-Solving appraisal, hopelessness and suicide ideation, evidence for a meditational model, Journal of Counseling Psychology, 91-98.

Elizabeth, B. Hurlock. (1993) Developmental Psychology. New Delhi; Tata Mc Graw-Hill Publishing.

Nelson-Jones, R. (2000). Life-skills Counseling. In Stephen Palmer (edr.) Introduction to Counseling and Psychotherapy, New Delhi. Sage Publication.

How to cite this article: S Surma, Sampathkumar (2016), Effects of Life - Skills Counseling In Enhancing Self-Sufficiency among High School Students, International Journal of Indian Psychology, Volume 3, Issue 4, No. 67, ISSN:2348-5396 (e), ISSN:2349-3429 (p), DIP:18.01.178/20160304, ISBN:978-1-365-39397-6 